\title{
Percepções e expectativas dos formadores e formandos do Instituto De Formação de Professores de Chongoene
}

Perceptions and expectations of trainers and trainees at the Chongoene Teacher Training Institute

Isabel Vasco Mamude Mataruca ${ }^{1}$

${ }^{1}$ Programa de Doutoramento em Educação da Universidade Eduardo Mondlane, Moçambique. Linha de Pesquisa: Formação Docente, Currículo, Diversidade e Aprendizagem em Contextos Formais e Não-Formais. E-mail: isabelmataruca@gmail.com, ORCID: https://orcid.org/0000-0001-5073-3147

\section{ARTICLE INFO}

Article history:

Received 2021-02-16

Accepted 2021-05-04

Available online 2021-05-04
Palavras-chave: Formação de professores. Expectativa. Prática docente. Ensino.

Keywords: Teacher training. Expectations; Teaching practice. Teaching.

RESUMO. Este estudo, de carácter exploratório e descritivo, foi desenvolvido com recurso ao paradigma interpretativista, seguindo uma abordagem qualitativa, integrando 54 participantes, distribuídos por dois grupos distintos: (i) formadores do Instituto de Formação de Professores de Chongoene e (ii) formandos do Instituto de Formação de Professores de Chongoene. O presente artigo tem como objectivo debater as percepções e expectativas dos formadores e formandos do Instituto de Formação de Professores de Chongoene sobre o novo modelo de Formação de professores do ensino primário e educadores de adultos. As vozes dos sujeitos entrevistados, dos grupos de formadores e formandos, sinalizam que há percepções e expectativas específicas de cada grupo que são vistas em ângulos diferentes. Os formadores estão conscientes da pressão que existe sobre o sistema educativo moçambicano, daí que no processo de ensino e aprendizagem demonstram muita preocupação com a qualidade do produto final a apresentar à sociedade. Entretanto, os formandos participantes neste estudo são unânimes no elogio ao desempenho profissional e à actuação dos seus formadores. Neste contexto, um grande desafio é colocado ao Instituto de Formação de Professores de Chongoene para preparar profissionais competentes, reflexivos, proactivos orientados para a profissionalização da actividade docente o que pressupõe a adaptação da sua cultura organizacional à administração e gestão de um curso flexível.

ABSTRACT. This exploratory and descriptive study was developed using the interpretive paradigm, following a qualitative approach, integrating 54 participants, divided into two distinct groups: (i) trainers from the Chongoene Teacher Training Institute and (ii) trainees from Chongoene Teacher Training Institute. This article aims to discuss the perceptions and expectations of the trainers and trainees of the Chongoene Teacher Training Institute about the new model for training primary 
school teachers and adult educators. The voices of the interviewed from the groups of trainers and trainees reveal that there are specific perceptions and expectations of each group that are seen in different angles. The trainers are aware of the pressure that exists on the Mozambican education system, that's why in the teaching and learning process they show great concern with the quality of the final product to be presented to the society. However, the trainees participating in this study are unanimous in praising the professional performance of their trainers. In this context, a great challenge is posed to the Chongoene Teacher Training Institute to prepare competent, reflective, proactive professionals oriented towards the professionalization of teaching activity, which presupposes the adaptation of its organizational culture to the administration and management of a flexible course.

\section{Introdução}

A formação de professores afigura-se como um tema amplo e cuja discussão, em função desta amplitude, tem envolvido diferentes aspectos, paradigmas e políticas. Diversos autores (GÓMEZ, 1992, CANDAU, 1993, LIBÂNEO; PIMENTA, 1999, ALARCÃO, 2001, CONTRERAS, 2002 e GASPAR; PEREIRA; OLIVEIRA; TEIXEIRA, 2015), em seus estudos abordam os paradigmas/modelos de formação do professor, questionam suas implicações no processo de ensino e aprendizagem e explicitam as competências e os saberes relativos a cada modelo de formação.

A formação, valorização e motivação dos professores no sistema educativo nacional apresenta-se como uma das acções prioritárias do Programa Quinquenal do Governo de Moçambique, pois para atender às transformações da sociedade moçambicana e responder aos desafios colocados pela realidade, exige-se um profissional da educação cada vez mais qualificado, capaz de adoptar novos procedimentos de ensino e assumir uma postura investigativa e reflexiva.

A esse respeito, o Programa Quinquenal do Governo de Moçambique (20152019) estabelece que é necessário "promover um Sistema Educativo inclusivo, eficaz e eficiente que garanta a aquisição das competências requeridas ao nível de conhecimentos, habilidades, gestão e atitudes que respondam às necessidades de desenvolvimento humano" (PQG 2015-2019, p.4).

A formação de profissionais reflexivos implica práticas docentes apoiadas na mobilização de um conjunto de saberes, transformando-os em acção, de forma a promover um ensino de qualidade (INDE, 2019).

Em outra perspectiva, a formação de profissionais que atendam às necessidades de uma população específica, formada por jovens e adultos, tem-se colocado como questão central nos debates contemporâneos. "O processo de escolarização dos jovens e adultos está relacionado aos sistemas formativos dos educadores, que, no enfoque específico da Educação de Jovens e Adultos (EJA), estão cada vez mais escassos no cenário educacional" (AMORIM; DUQUES, 2017, p.2).

Neste contexto, no presente trabalho, o objectivo é debater as percepções e expectativas dos formadores e formandos do Instituto de Formação de Professores de Chongoene (IFPC) sobre o novo modelo de Formação de professores do ensino primário e educadores de adultos em vigor em Moçambique, desde o ano de 2019. 


\section{Contextualização}

Este estudo teve lugar no IFPC, criado por despacho no 263/GM/MINEDH/2015, de 09 de Outubro, do Ministro da Educação e Desenvolvimento Humano de Moçambique, como resultado da extinção dos Institutos de Formação de Educadores de Adultos (IFEAs) criados pelo Diploma Ministerial $n^{\circ}$ 180/2010, de 03 de Novembro. A ideia da extinção dos IFEAs prende-se com o objectivo de formar apenas professores dotados de uma formação integrada por saberes plurais construídos, capazes de trabalhar com as pessoas de todas as idades.

A integração dos IFEAs na rede nacional dos IFPs e a adopção de um novo modelo de formação de professores $12^{\underline{a}}+3$ cria novos desafios institucionais e pedagógicos para os formadores do profissional de ensino que se pretende, na condução do processo de ensino e aprendizagem. Esta nova realidade na formação de professores propiciou a condução deste estudo cujo enfoque é despertar a dúvida, abalar as certezas e estimular a ousadia debatendo as percepções e expectativas dos formadores e formandos do Instituto de Formação de Professores de Chongoene sobre o novo modelo de Formação de professores do ensino primário e educadores de adultos.

\section{Referencial teórico}

"Conhecer o modo como os adultos constroem, elaboram e dão significado aos seus conhecimentos ajuda o formador a orientar as suas práticas pedagógicas, respeitando as subjectividades dos aprendentes com seus níveis, ritmos e suas singularidades" (MATARUCA, 2020, p.2). As teorias permitem a identificação das variáveis e suas relações, abrindo caminho à pesquisadora para encontrar a orientação da sua investigação. Segundo Garrison (2000, p.3), "... theory is a coherent and systematic ordering of ideas, concepts, and models with the purpose of constructing meaning to explain, interpret and shape practice".

Este estudo socorreu-se das teorias motivacionais de processo e de conteúdo. Nas teorias de processo seleccionámos a Teoria do estabelecimento de objectivos de Locke; Latham (1990) e a Teoria da expectativa de Vroom (1964). Nas teorias de conteúdo, o estudo apoiou-se na Teoria das necessidades de Maslow (1954) e na Teoria bi-factorial de Herzberg (1966). As teorias de processo ajudaramnos a entender como funciona a motivação enquanto as de conteúdo apoiaram-nos na identificação e explicação dos factores motivacionais dos formadores e formandos do IFPC. Assim, o recurso às teorias dos dois grupos (de conteúdo e de processo) permitiu interpretar o modelo de desempenho e de satisfação dos participantes deste estudo, determinando, assim, os seus níveis motivacionais.

\section{Metodologia}

Nesta pesquisa recorreu-se ao paradigma interpretativista, seguindo uma abordagem qualitativa buscando significados, motivações, aspirações, crenças, valores e atitudes dos formadores e formandos do IFPC na implementação do novo modelo de formação de professores em Moçambique.

Para Creswell (2007), os procedimentos da pesquisa qualitativa são caracterizados como indutivos, emergentes e determinados pela experiência do pesquisador na recolha e análise de dados. Assim, a presente pesquisa adopta 0 método indutivo e tendo em conta os objectivos da pesquisa, é exploratória e descritiva, tendo privilegiado a entrevista semi-estruturada e a observação na 
recolha de dados. Um dos aspectos característicos deste estudo foi a importância que a pesquisadora atribuíu à perspectiva dos formadores e formandos do IFPC, a qual foi captada essencialmente a partir do seu discurso. Neste sentido, a entrevista teve um papel importante a desempenhar, já que ela foi utilizada para recolher dados descritivos na linguagem do próprio sujeito, permitindo à pesquisadora desenvolver intuitivamente uma ideia sobre a maneira como o sujeito interpreta aspectos do processo de ensino e aprendizagem. Foram feitas perguntas abertas, para permitir aos entrevistados expressar livremente as suas ideias, sentimentos e emoções, o que deu para perceber que alguns participantes falavam com paixão, muitas vezes sem esconder a fé com que defendem seus ideais e demonstrando reviver as emoções experimentadas, ilustravam o que diziam com situações que haviam vivenciado, o que facilitou que se cumprisse com o recomendado por Stake (2009, p. 82), segundo o qual, "O propósito para a maior parte dos entrevistadores não é obter simples respostas de sim ou não, mas a descrição de um episódio, uma ligação entre factos, uma explicação".

Cumpridas todas as questões éticas e aplicando a estratégia de amostragem em Bola de Neve, a recolha de dados teve início a 13 de Junho e o seu terminus a 30 de Julho, via telefone. Com efeito, este processo foi facilitado pelo emprego das ferramentas comunicativas da Internet que permitiram, em tempo oportuno, situações variadas de interacção com os participantes neste estudo. Infelizmente, nestas entrevistas, que tinham uma duração média de 25 minutos, só podíamos captar os aspectos falados da entrevista, pois não reflectiam o ambiente, o contexto, a linguagem corporal e a sensação geral de cada formando participante neste estudo.

Mais tarde, após o relaxamento das medidas de prevenção à COVID-19, em meados do mês de Outubro de 2020, regressámos ao IFPC para a observação de algumas aulas do modelo $12^{\mathrm{a}}+3$. Por nossa iniciativa e, em coordenação com a direcção pedagógica, seleccionámos as disciplinas de Psicologia de Aprendizagem e Estrutura das Línguas Moçambicanas para a actividade de observação.

O estudo assumiu a forma de um estudo de caso múltiplo, integrando 54 participantes, considerando-se cada sujeito um caso ou unidade de análise (MILES; HUBERMAN, 1994). Na acepção de Stake (2009), tratou-se de um estudo de caso colectivo, porque procurou-se compreender os diversos elementos que contribuem no processo de formação docente através do estudo da prática dos formadores e formandos do IFPC. Cada participante foi informado sobre os objectivos da entrevista, bem como da liberdade de responder ou não às questões que lhes foram colocadas e, com a autorização dos mesmos, foram gravadas as entrevistas em suporte magnético e posteriormente feita a transcrição codificada de acordo com as normas para a transcrição de entrevistas gravadas, retiradas de Preti (1999). Com o objectivo de proteger a identidade dos participantes neste estudo, conforme defendido por Bogdan;Biklen (1994), utilizámos os seguintes códigos: FPn nas citações dos formadores e AFn nas citações dos Formandos do Modelo $12^{\underline{a}}+3$ entrevistados, onde $n$ representa o número atribuído a cada entrevistado da nossa amostra.

Com o apoio do software de análise qualitativa de dados MAXQDA, procedemos à transcrição das entrevistas previamente gravadas em suporte áudio, organizámos o corpus de dados, analisámos, visualizámos e projectámos os resultados. Assim, seguindo a estrutura básica da análise de conteúdo, recortámos os textos das entrevistas em unidades de contexto que "servem de unidade de compreensão para codificar a unidade de registo e corresponde ao segmento da 
mensagem, cujas dimensões (superiores as da unidade de registo) são óptimas para que se possa compreender a significação exacta da unidade de registo" (BARDIN, 2011, p. 137), e unidades de registo que "é a unidade de significação a codificar e corresponde ao segmento de conteúdo a considerar como unidade base, visando a categorização e a contagem frequencial" (BARDIN, 2011, p. 134). Neste contexto, com base nas categorias emergentes, foram organizadas as partes da apresentação dos resultados com seus temas centrais, nas quais foram construídas tabelas da tabulação quantitativa para ilustrar as análises a fazer, considerando-se o referencial teórico proposto.

\section{Resultados}

No processo de recolha de dados, efectuaram-se entrevistas envolvendo um total de 54 participantes, dos quais $50 \%$ são do sexo feminino, distribuídos de acordo com a tabela 1 . As idades variam de 18 a 48 anos, e o tempo de serviço dos formadores, de três a 35 anos.

\section{Tabela 1. Distribuição dos participantes de entrevistas por funções que desempenham}

\begin{tabular}{|c|c|}
\hline Participantes envolvidos & $n$ \\
\hline Gestores do IFP de Chongoene & 2 \\
\hline Formadores de professores primários e de educadores de adultos & 14 \\
\hline Formandos do IFPC Modelo $12^{\underline{a}}+3$ & 38 \\
\hline $\begin{array}{l}\text { TOTAL DE PARTICIPANTES } \\
\end{array}$ & 54 \\
\hline
\end{tabular}

Fonte: O autor (2020).

Um dos grandes desafios que os participantes deste estudo enfrentam no processo de ensino e aprendizagem é a falta de formação profissional específica para a função de formador de professores, como se pode inferir da colocação que se segue: "Não passámos por uma instituição direccionada à formação de formadores para os IFPs, apenas por aquelas outras formações para professores primários e secundários"(FP2). E mais adiante a formadora em ensino bilingue rematou: "Não existe formação específica para formadores, eu não tive nenhum curso como formadora em ensino bilingue" (FP4), secundado por um outro participante nos termos seguintes: "Quando chegámos aqui tivemos que nos adaptar, sermos criativos, saber como preparar alguém para ir ensinar crianças ou adultos" (FP12).

Um outro desafio não menos importante é a necessidade urgente de especialização dos formadores, como se pode inferir no seguinte comentário:

- "Julgo que a questão de especialização é o que se pretende num futuro não distante. Por outro lado, formar alguém para ensinar a crianças e ao mesmo tempo ensinar adultos é um pouco desastroso" (FP14).

É neste ambiente desafiante que os participantes desta pesquisa iniciaram em 2019 com a implementação do novo modelo de formação de professores em Moçambique. O objectivo do novo modelo de formação de professores $\left(12^{a}+3\right)$ é "produzir professores dotados de uma formação integrada por saberes plurais construídos, capazes de trabalhar com as pessoas de todas as idades, desde o ensino primário à educação de adultos" (MATARUCA, 2020, p.4). Os participantes deste estudo são unânimes em afirmar que, apesar de o novo modelo ser bemvindo, apresenta certas lacunas cuja solução é urgente, designadamente: (i) grande parte dos conteúdos está mais virada para o ensino primário; (ii) o modelo dispõe de apenas um semestre para o tratamento das questões relacionadas com a educação 
de adultos; (iii) falta de manuais para a preparação adequada de educadores de adultos; (iv) devido à escassez de centros de alfabetização e educação de adultos, prevê-se que a maioria dos formandos realize o seu estágio em escolas do ensino primário.

\section{Formadores do IFPC}

As percepções e expectativas dos formadores do IFPC emergiram nos dados e constituíram-se em unidades de análise às suas percepções, expectativas e motivações. Assim, foram seleccionadas e definidas as categorias de respostas, representadas na Tabela 2:

Tabela 2. Categorias emergentes e respectivas unidades de registo / Formadores

\begin{tabular}{|c|c|c|}
\hline \multirow[t]{2}{*}{ Categoria emergente } & \multicolumn{2}{|c|}{ Unidades de registo } \\
\hline & Segmentos & Percentagem \\
\hline Modelo $12^{\underline{a}}+3$ & 54 & 25.50 \\
\hline Motivação & 40 & 18.87 \\
\hline Extinção dos IFEAs & 34 & 16.03 \\
\hline $\begin{array}{l}\text { Consideração da(s) forma(s) como os formandos } \\
\text { aprendem }\end{array}$ & 29 & 13.68 \\
\hline Centralidade na prática docente & 22 & 10.37 \\
\hline Reconhecimento da EJA como área específica & 17 & 8.01 \\
\hline Apoio à melhoria do trabalho dos formandos & 16 & 7.54 \\
\hline $\begin{array}{l}\text { TOTAL } \\
\end{array}$ & 212 & 100,00 \\
\hline
\end{tabular}

$$
\text { Fonte: O autor (2020). }
$$

Para se efectuar a análise de conteúdo defendida por Bardin (2011), emergiram sete categorias nas quais couberam 212 Unidades de Registo (UR).

Os interpretativistas estabelecem diferença epistemológica (is it knowable ?1) fundamental entre ciências sociais e ciências naturais. A perspectiva epistemológica interpretativista sustenta que "a realidade social não é apenas para ser observada, mas antes interpretada" (CORBETTA, 2003, p.21). Neste contexto, em seguida procura-se, resumidamente, descrever cada uma destas categorias.

\subsection{Categoria "Modelo $12^{\mathrm{a}+3}$ "}

Apesar de serem unânimes na apreciação positiva do modelo, os formadores do IFPC apresentam algumas dificuldades como se pode constatar nas falas seguintes de alguns dos participantes: "Temos certas dificuldades com equipamentos e material didáctico" (FP7) e "não é só introduzir andragogia em si na formação do educador de adultos é preciso que os instrumentos também estejam lá" (FP9) e que "a dosagem dos materiais é desequilibrada, favorece mais o ensino primário bem como há formadores a trabalhar com algumas novas disciplinas para as quais não tiveram formação especifica" (FP11). Ainda abordando as dificuldades na implementação do novo modelo, FP2 relata que "para ministrar as próprias aulas é um dilema porque não há instrumento orientador, dependemos dos planos

\footnotetext{
${ }^{1}$ É reconhecível? (livre tradução)
} 
analíticos nacionais, mas seria bom termos um programa e podermos digerir em grupo de disciplina aqui na instituição porque provavelmente teríamos sugestões metodológicas para o tratamento de uma determinada aula" (FP2) e "A falta do material não é só para o formando, mas para nós também como formadores" (FP12).

Mesmo assim, os participantes deste estudo reconhecem haver ganhos que justifiquem o sucesso do modelo, como se pode inferir nas seguintes colocações:

- "Tendo em conta a realidade do país, o nosso formando sai daqui preparado para trabalhar com as duas camadas, trabalha com as crianças mas lá na comunidade onde existem jovens e adultos que não sabem ler nem escrever [...] deve estar também preparado para trabalhar com aqueles jovens e adultos" (FP5).

- "O novo modelo é bem vindo, é mais abrangente, porque esses formandos que estamos a trabalhar com eles ao saírem daqui para o campo vão estar em condições de lidar com qualquer tipo de aluno sobretudo na perspectiva de uma educação inclusiva porque poderão lá encontrar uma criança já com certas necessidades educativas especiais eles já estão a serem preparados aqui para saber lidar com este aluno" (FP13).

Apesar de um dos participantes reconhecer que "o modelo em si reduz o número de dificuldades, primeiro o número de formandos por turma facilita ao formador trabalhar as dificuldades de forma particularizada; segundo o volume dos conteúdos saindo do modelo de $10^{\underline{a}}+2$ que apenas trabalham em oito semanas em regime de blocos [...] neste modelo em que as disciplinas são semestrais há espaço suficiente para tratar os conteúdos de forma paulatina até superarmos as dificuldades; Terceiro o plano analítico é nacional e sempre temos tido encontros com formadores de outras instituições de formação de professores para intercâmbio" (FP12).

\subsection{Categoria “Motivação"}

Os participantes deste estudo são formadores profissionais que no seu quotidiano se comportam no sentido de atingir os objectivos definidos para o IFPC, ao mesmo tempo em que procuram alcançar também os seus próprios objectivos individuais. O seu envolvimento com a organização é muito forte, como se pode inferir na passagem seguinte "O segredo é que aqui não há formador, não há formando e não há gestor, todos somos trabalhadores" (FP1). Outros participantes pronunciaram-se nos seguintes termos: "É normal como formadores trabalharmos até $21 \mathrm{~h}$ quando a realidade do trabalho obriga [...] nós trabalhamos mais horas e sem esperar nenhuma remuneração extra" (FP5); "Me sinto bem a trabalhar com esta modalidade de ensino, tenho gosto de pôr alguém a trabalhar para o bem estar das crianças e para a comunidade e sociedade no geral" (FP10).

Os formadores do IFPC consideram o seu trabalho quotidiano desafiante e sentem-se orgulhosos, pois realizam um trabalho seguro e socialmente reconhecido numa organização localizada num povoado sem nenhum tipo de poluição. Neste contexto, podemos afirmar que tanto as necessidades de baixo nível (fisiológicas e de segurança) como as de alto nível (sociais, de estima, de auto-realização) elencadas na Teoria da Hierarquia das Necessidades de Maslow estão minimamente realizadas. Mesmo assim, prevalece entre alguns formadores o desejo de crescimento na carreira e a forte necessidade de desenvolvimento de competências e habilidades profissionais. Os participantes deste estudo estão motivados e contribuem para um bom clima organizacional, trabalham satisfeitos e diariamente procuram dominar o trabalho que realizam, identificam o sucesso do 
IFPC como seu e por isso desempenham um trabalho que eles consideram de qualidade.

Concordando com Silva (2008, p.204), o desempenho dos formadores do IFPC é "resultado de dois factores: nível de habilidade e motivação, que pode ser expresso pela equação:

\section{Desempenho $=f$ (Habilidade $\times$ Motivação)} variáveis".

Motivação é um assunto complexo, muito pessoal, e influenciado por diversas

Aliás, uma das acções prioritárias inseridas no Programa Quinquenal do Governo de Moçambique (2015-2019), era "fortalecer a formação, valorização e motivação dos professores no sistema da educação" (p.4).

Segundo Locke (1984), a satisfação no trabalho está associada a uma série de consequências organizacionais e esta série de possíveis consequências e reacções é muito variada e complexa, pois a satisfação no trabalho é seguramente uma resposta emocional, que se afasta, em larga medida, não só da certeza de uma aprendizagem real e efectiva de todos os conteúdos ensinados, mas também da Motivação Intrínseca que a médio e longo prazo tem a capacidade de promover a aprendizagem e o gosto/motivação de aprender "[...] na troca permanente de experiências com colegas" (FP7).

\subsection{Categoria "Extinção dos IFEAs"}

Nesta categoria, a subcategoria "Frustração" foi uma das que mais se destacou na entrevista com os formadores do IFPC. Segundo Silva (2008, p.208), "a frustração é uma resposta negativa ao bloqueio de uma meta desejada e resulta em uma forma defensiva de comportamento". De facto, esta subcategoria está directamente relacionada com a decisão de extinguir os IFEAs. Com efeito, a partir do ano lectivo de 2016 e em cumprimento do despacho no 263/GM/MINEDH/2015, de 09 de Outubro, do Ministro da Educação e Desenvolvimento Humano (MINEDH), o Instituto de Formação de Educadores de Adultos (IFEA) de Chongoene passou a designar-se apenas por Instituto de Formação de Professores de Chongoene. Esta decisão colheu de surpresa o corpo docente da instituição, que ficou negativamente marcado, pois decorria em fase experimental de implementação, o novo currículo de alfabetizadores profissionais, que introduzia a formação de técnicos com um nível de décima classe, para um curso de três anos.

Um dos formadores pronunciou-se nos seguintes termos: "O que me marcou de facto negativamente é de terem introduzido um Curso de $10^{a}+3$ para Educadores de Adultos onde nós trabalhámos com material que aquilo era draft e que foi extinto com aquele material draft [...] então para mim é uma coisa que me marcou muito pois me interrogo: onde é que vamos com isto? nem se fez avaliação, mas chegou um momento extinguiu-se sem nenhuma explicação" (FP10).

A subcategoria "Marginalização do Educador de adultos" refere-se aos Educadores formados pelos IFEAs que enfrentam sérias dificuldades de enquadramento profissional. $\mathrm{O}$ Educador de Adultos não encontra enquadramento no Qualificador Nacional, o que resulta na falta de reconhecimento e enquadramento profissional. "Se formos a fazer estatística agora podemos constatar que, provavelmente, $5 \%$ para não dizer que todo o nosso produto está a trabalhar nas escolas primárias" (FP1). De facto, Soares (2006), citado em Amorim; Duques, (2017, p.8) já afirmava que "a pouca atenção às especificidades da EJA nos 
processos de formação conduz à desqualificação profissional" alinhando com Moura (2009), que deplora a inexistência de instituições específicas que realizam a formação de educadores de jovens e adultos.

\subsection{Categoria "Consideração da(s) Forma(s) como os formandos Aprendem"}

Os formadores do IFPC estabelecem com os seus formandos, como determina o Plano Curricular do Curso de Formação de Professores do Ensino Primário e Educadores de Adultos "uma relação biunívoca, em que a aprendizagem depende da participação activa do formando na aprendizagem e na construção do seu próprio conhecimento, evitando assim a reprodução e a memorização do que Ihes é transmitido" (INDE, 2019, p.6). Eles preocupam-se, permanentemente, com a forma como os seus formandos aprendem e "cabe a cada um redobrar os esforços usando métodos adequados porque cada formando vem da sua casa, tem sua maneira de ser e aí temos que ensinar tudo e a todos, mas respeitando as particularidades de cada um" (FP7). Os formadores vêm diferença "em termos de tratamento dos conteúdos com crianças porque aí os jogos são infantis, trabalham mais com base nos jogos e a criança aprende melhor brincando, mas já no adulto valoriza-se mais a experiência que ele traz [...] você quer tratar um tema, expõe o tema e promove um debate, uma conversa onde cada adulto vai dizer o que entende, partilha a experiência que tem e com base nessa experiência vamos compilar os dados para com ele construir conhecimento" (FP15).

Os participantes deste estudo mobilizam todas as suas energias partindo do pressuposto de que "Onde há trabalho as dificuldades não faltam, mas para o currículo deste curso de formação de professores primários e educadores de adultos praticamente não há défice de material didáctico" (FP4). Esta fala do formador FP4 insere em si uma contradição sobre material didáctico. Provavelmente este participante pretendeu ser politicamente correcto porque, de facto, há carências assinaláveis de material didáctico no IFPC, facto reconhecido pelos gestores da Direcção Nacional de Alfabetizaçao e Educação de Adultos entrevistados.

\subsection{Categoria "Centralidade na prática docente"}

Todo o trabalho do docente, o que implica necessariamente toda a sua actividade em contexto de sala de aula, pode representar um acto avaliativo, uma decisão, como afirma Stiggins (2008), uma reflexão, uma acção pensada para influenciar o processo de ensino e aprendizagem de cada aprendente ou grupo na turma. O conhecimento prático, isto é, a "cultura docente em acção", resulta da articulação de saberes disciplinares e curriculares, da formação profissional e saberes experienciais (TARDIF, 2002, citado em BORGES, 2014, p.42), conforme destacado a seguir: "Apresentei proposta de alastramento de tempo de abordagem dos conteúdos, de módulos para disciplinas semestrais... para se evitar a descontinuidade do currículo" (FP3).

$\mathrm{Na}$ interação com os formadores, podemos deduzir que no seu imaginário vivem com intensidade a actividade a que estão afectos. Vivenciamos momentos de emoção e firmeza nas suas falas o que nos leva a inferir que os formadores do IFPC, apesar de enfrentarem dificuldades de várias ordens, trabalham afincadamente para a realização dos objectivos declarados no Plano curricular do novo modelo de formação de professores.

Durante a observação feita às aulas ministradas por formadores das disciplinas de Psicologia de Aprendizagem e Estrutura das Línguas Moçambicanas, testemunhámos a dedicação e a cultura docente em acção. De facto, os dois formadores assistidos mantêm arquivos bem estruturados dos conteúdos a ministrar 
bem como os respectivos planos de aulas. Demonstraram gosto e vocação do que fazem como formadores. As actividades planificadas para cada uma das aulas despertavam curiosidade e muito interesse nos formandos e desenvolveram sua aprendizagem significativa, mostraram-se interessantes, adequadas e contextualizadas.

\subsection{Categoria "Reconhecimento da EJA como área específica"}

A formação de profissionais que atendam às necessidades de uma população específica, formada por jovens e adultos, tem-se colocado como questão central nos debates contemporâneos. "O processo de escolarização dos jovens e adultos está relacionado aos sistemas formativos dos educadores, que, no enfoque específico da Educação de Jovens e Adultos (EJA), estão cada vez mais escassos no cenário educacional" (AMORIM; DUQUES, 2017, p.2).

Os participantes deste estudo reconhecem a EJA como área específica enquadrando a questão da formação dos educadores de jovens e adultos numa problemática mais ampla, que é a da própria constituição da educação de adultos como campo pedagógico, defendendo por isso a necessidade de separação da formação de professores primários e de educadores de jovens e adultos. Contudo, pensar na formação do educador de jovens e adultos, no actual contexto socioeconômico, político e cultural moçambicano exige uma avaliação e uma revisão da prática educativa e da formação inicial e continuada desses educadores. "Para mim há necessidade de separar a formação de professores primários da formação de educadores de adultos, estas duas áreas devem existir separadas, pois são duas coisas bem diferentes, são duas modalidades bem diferentes, essas coisas nem deviam estar juntas, uma área não tem nada a ver com a outra, vamos ter professores formados em quantidade cuja qualidade vai ser lamentável; é uma área específica e com metodologias próprias, uma coisa não tem nada a ver com a outra" (FP6).

\subsection{Categoria "Apoio à Melhoria do Trabalho dos formandos"}

No processo de ensino e aprendizagem os formadores demonstram muita preocupação com a qualidade do produto final a apresentar à sociedade. Neste contexto, não só se apoiam na base material de ensino existente no IFPC, como também se dedicam a procurar alternativas pedagógicas de apoio à melhoria do trabalho dos seus formandos, como se pode inferir da colocação seguinte: "[...] gravo áudio, criamos um grupo de whatsapp, gravo pronunciando algumas palavras do alfabeto...eu gravo o alfabeto das línguas Mocambicanas e envio naquele grupo de whatsapp, sim. E eles vão escutando aquilo e vão praticando" (FP4). Um outro formador interpelou dizendo "E tendo em conta que nós estamos a trabalhar com adultos, às vezes um tema fala do jogo e como exemplo, no jogo de futebol devíamos ter uma bola, mas nós não temos a bola... não vamos deixar de dar aula porque não temos a bola. Com base no material local pode-se produzir alguma coisa para o tema ser tratado [...." (FP12).

Os formadores do IFPC incentivam os seus formandos a usar a internet e a recorrerem a bibliotecas de outras instituições de ensino existentes na capital provincial. 


\section{Formandos do Modelo $12^{\mathrm{a}}+3$}

As motivações e expectativas dos formandos do IFPC sobre o novo modelo da sua formação emergiram dos dados empíricos obtidos através da aplicação de entrevistas semi-estruturadas e constituíram-se em unidades de análise. Deste modo, emergiram as categorias de respostas, representadas na Tabela 3:

\section{Tabela 3 - Categorias emergentes e respectivas unidades de registo /} Formandos

\begin{tabular}{lcc}
\hline \multicolumn{1}{c}{ Categorias emergentes } & \multicolumn{2}{c}{$\begin{array}{c}\text { Unidades de registo } \\
\text { Segmentos }\end{array}$} \\
\hline Pificuldades / barreiras dos formandos & 63 & $20 \%$ \\
\hline Expectativas dos formandos & 61 & $19 \%$ \\
\hline Contribuição da formação profissional para a EJA & 36 & $11 \%$ \\
\hline Desempenho académico & 35 & $11 \%$ \\
Oportunidade de nova escolha de curso & 33 & $10 \%$ \\
\hline Avaliação do novo Plano Curricular & 33 & $10 \%$ \\
Necessidade de uma formação específica do Educador & 30 & $9 \%$ \\
de Adultos & 21 & $7 \%$ \\
Sugestões/ideias dos formandos & 7 & $2 \%$ \\
\hline Pontos fortes do novo Plano Curricular & 319 & $100 \%$ \\
\hline \multicolumn{2}{c}{ TOTAL } & \\
\hline
\end{tabular}

\section{Fonte: $O$ autor (2020).}

Os formandos, apesar de identificarem dificuldades do modelo $12^{\underline{a}}+3$ na relação com os colegas e na escassez de recursos e materiais didácticos, estão muito motivados para concluírem com sucesso esta formação e alimentam expectativas muito altas.

Aliás, no Plano Curricular do Curso de Formação de Professores do Ensino Primário e Educadores de Adultos (2019) "espera-se que o formando aprenda a aprender a ensinar através do contacto com estratégias participativas, num ambiente em que todos ensinam e aprendem, assumindo, o formador, o papel de organizadormediador" (p.26).

Em nossa opinião, AF3 resume o grau de expectativas dos formandos deste novo modelo quando afirma: "A minha expectativa em relação a este modelo de formação de professores é garantir o bom desempenho no processo de ensino e aprendizagem, garantir boa qualidade de ensino, garantir a inclusão de todos, fazer com que as pessoas que sentem fora ou que se sentiam fora do processo de ensino e aprendizagem possam estar dentro. Como futura professora gostaria de envolver os pais e encarregados de educação no desenvolvimento dos seus educandos porque isso também é muito importante... mais gostaria de dizer que a minha expectativa é ser uma boa professora, ser um bom exemplo, garantir a inclusão e atender com humanismo as pessoas com necessidades educativas especiais" (AF3).

O depoimento do participante AF3, vai ao encontro da expectativa do MINEDH em relação ao graduado do Curso de Formação de Professores do Ensino Primário e Educadores de Adultos, onde se espera que seja um profissional idóneo e crítico, com elevado espírito patriótico, que ame as crianças e adultos, fluente na língua de ensino, exemplar na prevenção de doenças e preservação do ambiente, respeitador e cumpridor das leis do país e dos princípios éticos e deontológicos da profissão docente, capaz de mobilizar criativamente os saberes necessários para planificar, organizar e gerir o processo de ensino e aprendizagem, de liderar e 
participar proactivamente em processos de desenvolvimento na escola e na comunidade (INDE, 2019).

Uma das dificuldades apontadas por quase todos os formandos está relacionada com um dos pilares do saber, como recomendado pela Comissão Internacional sobre Educação para o Século XXI (1998), e plasmado no Plano Curricular: aprender a ser e aprender a conviver com os outros. Este pilar contribui para a formação integral do profissional que se pretende e levanta problemas culturais e de integração.

De facto, e tendo em conta que os formandos do IFPC são provenientes de várias províncias do país, eles transportam consigo seus hábitos, costumes e culturas. Estes e outros elementos subjectivos colocam aos formandos um desafio de integração e de aprendizagem colectiva com vista a construírem pontes facilitadoras da troca de experiências enriquecedoras do desempenho individual e colectivo.

Neste contexto, um grande desafio é colocado às instituições de formação de professores e educadores de adultos para preparar profissionais competentes, reflexivos, proactivos orientados para a profissionalização da actividade docente 0 que pressupõe a adaptação da sua cultura organizacional à administração e gestão de um curso flexível (INDE, 2019).

O Plano Curricular do Curso de Formação de Professores do Ensino Primário e Educadores de Adultos assenta na profissionalização como a pedra angular de todo o processo, em torno do qual o desenvolvimento de competências no domínio pessoal e social, de conhecimentos científicos e de habilidades inerentes à profissão, são construídos (INDE, 2019, p.4).

"Foi positivo terem introduzido este novo modelo de curso porque estamos a ser preparados com tempo suficiente para uma aprendizagem significativa para lidarmos com os alunos de todas as faixas etárias" declarou o formando (AF 34).

Refira-se que o presente Plano Curricular, assente na linha dos modelos construtivistas, ressalta a necessidade de se conceber uma formação contínua que contribua para a mudança educacional, para a redefinição da profissão docente e que encara os professores em todas as suas dimensões - individual, colectiva, profissional e organizacional (INDE, 2019, p.26).

Numa leitura atenta ao conjunto de categorias emergentes do imaginário dos formandos do modelo $12^{\underline{a}}+3$, podemos deduzir que reina muitas expectativas no seio dos futuros profissionais e, aparentemente, apesar de estarem a frequentar um curso que engloba educação de adultos, a maioria, representando $96,8 \%$ dos formandos, vê com entusiasmo a necessidade de uma formação específica do educador de adultos. Pensamos que, muito cedo, os formandos deste modelo participantes neste estudo, compreenderam que "ser educador de jovens e adultos implica disposição para aproximações que passeiam entre os saberes legitimados no campo das ciências e saberes experienciados e legitimados no reencontro com o espaço escolar" como defendem Amorim; Duques (2017, p.5).

\section{Considerações finais}

Este estudo, de carácter exploratório e descritivo, foi desenvolvido com recurso ao paradigma interpretativista, seguindo uma abordagem qualitativa, integrando 54 participantes do IFPC. Desta forma, importa salientar que os resultados por nós obtidos não se podem generalizar a outros contextos formativos e geográficos. Esperamos, no entanto, que os mesmos contribuam para a 
compreensão das dinâmicas pedagógicas, em particular no que às percepções e expectativas dos formadores e formandos se refere. Não se pretende, neste estudo, encontrar um uníssono de motivações, aspirações, crenças, valores e atitudes num coral de tantas vozes, com tão diferentes timbres e tonalidades. Interessava-nos descobrir a variedade de pontos de vista no assunto em questão e o que fundamenta e justifica esses potenciais diferentes pontos de vista.

Uma primeira conclusão que se pode tirar dos dados obtidos com esta pesquisa é a de que, muitos dos formadores agora afectos no IFPC não tiveram uma formação específica para lidar com os princípios andragógicos. Se tomarmos em conta o novo paradigma de formação de professores e a necessidade de produzirmos um professor polivalente, capaz de lidar com alunos de todas as idades, julgamos que seria interessante a organização de programas de actualização ou mesmo formação especializada dos formadores para que eles desempenhem com competência a tarefa incumbida. Há necessidade de munir os formadores de princípios e pressupostos da aprendizagem de adultos, pois sem estas ferramentas fica difícil garantir a qualidade exigida pelo novo currículo na formação do professorreflexivo, do professor-pesquisador, da epistemologia da prática, um professor e educador de adultos que se deve "configurar como mediador entre o conhecimento científico e os objectivos da sociedade e os interesses e aspirações dos seus alunos e não um mero reprodutor de conhecimentos" (INDE, 2019, p.6). Aliás o próprio Plano Curricular já advogava que "Tendo em conta a formação unificada, integrada, inclusiva e inacabada, torna-se necessário que o professor e educador de adultos tenha ao seu dispor um vasto leque de perspectivas e teorias que o ajudem na escolha das condições indispensáveis para a construção de uma imagem do que é, realmente, ser professor" (INDE, 2019, p.50).

Por seu turno os formandos, apesar de identificarem dificuldades do modelo $12^{a}+3$ na relação com os colegas e na escassez de recursos e materiais didácticos, estão muito motivados para concluírem com sucesso esta formação e alimentam expectativas muito altas.

Aliás, no Plano Curricular do Curso de Formação de Professores do Ensino Primário e Educadores de Adultos (2019) "espera-se que o formando aprenda a aprender a ensinar através do contacto com estratégias participativas, num ambiente em que todos ensinam e aprendem, assumindo, o formador, o papel de organizadormediador" (p.26).

Uma das dificuldades apontadas por quase todos os formandos está relacionada com um dos pilares do saber, como recomendado pela Comissão Internacional sobre Educação para o Século XXI (1998), e plasmado no Plano Curricular: aprender a ser e aprender a conviver com os outros. Este pilar contribui para a formação integral do profissional que se pretende e levanta problemas culturais e de integração.

De facto, e tendo em conta que os formandos do IFPC são provenientes de várias províncias do país, eles transportam consigo seus hábitos, costumes e culturas, estes e outros elementos subjectivos colocam aos formandos um desafio de integração e de aprendizagem colectiva com vista a construírem pontes facilitadoras da troca de experiências enriquecedoras do desempenho individual e colectivo.

Por acreditarmos que este trabalho trouxe relevantes contribuições para o conhecimento do imaginário dos formadores e formandos do IFP de Chongoene, propomos a continuidade das pesquisas sobre este conceito nos seguintes aspectos: (i) Desenvolvimento de uma ferramenta de gestão de processos e pessoas para instituições de formação de professores, aliando a gestão pedagógica, 
tecnológica e administrativa; (ii) Contribuição da linguística no desenvolvimento dos materiais didácticos e no atendimento aos formandos; (iii) Desenvolvimento de metodologias de avaliação de processos e de resultados do trabalho quotidiano do formador do IFPC. Há muito que pesquisar e muitos vazios ainda por serem preenchidos na construção do conhecimento dos participantes desta pesquisa. Apesar de se tratar de uma instituição de formação com experiência reconhecida e planos de estudos detalhados, organização e funcionamento excelente, os resultados obtidos no estudo evidenciam algumas convergências nas opiniões dos formandos e formadores relativamente a alguns aspectos críticos que apontam para a necessidade de: um ajustamento do plano curricular; uma formação específica para os formadores; maior participação do formador na avaliação das práticas pedagógicas e uma reestruturação na colaboração entre o IFPC, escolas primárias e centros de alfabetização e educação de adultos.

\section{REFERÊNCIAS}

ALARCÃO, Isabel (org). Escola reflexiva e nova racionalidade. Porto Alegre: Artmed, 2001.

AMORIM, António; DUQUES, Maria Luíza Ferreira. Formação de educadores de EJA: caminhos inovadores da prática docente. Educação Revista Quadrimestral. Porto Alegre, v. 40, n. 2, p. 228-239, maio-ago. 2017.

BARDIN, Laurence. Análise de conteúdo. Tradução Luís Antero Reto, Augusto Pinheiro. Edição revista e ampliada. São Paulo: Edições 70, 281p., 2011.

BOGDAN, Robert C.; BIKLEN, Sari Knopp. Investigação qualitativa em Educação, Uma Introdução à Teoria e aos Métodos. Colecção Ciências da Educação. Porto: Porto Editora. 1994.

BORGES, Maria Leonor. Profissionalidade docente: da prática à praxis. Investigar em Educação - II a Série, Número 2, 2014.

CANDAU, Vera Maria. Rumo a uma nova Didática. Petrópolis, RJ: Vozes, 1993.

CONTRERAS, José. A autonomia de professores. Tradução de Sandra Trabucco Venezuela. 2. ed. São Paulo: Cortez, 2012.

CORBETTA, Piergiorgio. Social Research: Theory, Methods and Techniques. Translated by Bernard Patrick. First published. London: SAGE Publications, 2003.

CRESWELL, John W. Qualitative Inquiry \& Research Design: choosing among five approaches (2nd ed.). Thousand Oaks: Sage, 395p, 2007.

DELORS, Jacques et al.. Educação Tesouro a Descobrir. Relatório para a UNESCO da Comissão Internacional sobre Educação para o Século XXI. São Paulo: Cortez Editora, 1998.

Despacho Ministerial no 263/GM/MINEDH/2015, de 09 de Outubro, que extingue os os Institutos de Formação de Educadores de Adultos, 2015.

Diploma Ministerial 180/2010, de 3 de Novembro. Cria os Institutos de Formação de Educadores de Adultos, 2010.

GARRISON, Randy. Theoretical Challenges for Distance Education in the 21st Century: A Shift from Structural to Transactional Issues. The International Review of Research in Open and Distributed Learning, 1(1), 2000. https://doi.org/10.19173/irrodl.v1i1.2

GASPAR, Maria Ivone (Coord.); PEREIRA, Alda; OLIVEIRA, Isolina; TEIXEIRA, António. Modelos para Ensinar: Escolhas do Professor. 1를 Edição. Lisboa: Chiado Editora, 2015. 
GÓMEZ, Angel Pérez. O. O Pensamento Prático do Professor - A formação do Professor como profissional reflexivo. IN: NÓVOA. A. (Org.) Os Professores e a sua Formação. Lisboa: Dom Quixote, 1992.

HERZBERG, Frederick. Work and the nature of man. Londres: Crosby Lockwood Staples, 1966.

INDE (INSTITUTO NACIONAL DE DESENVOLVIMENTO DA EDUCAÇÃO). Plano Curricular do Curso de Formação de Professores do Ensino Primário e Educadores de Adultos. 1를 Edição.Maputo, 2019.

LIBÂNEO, José Carlos; PIMENTA Selma Garrido. Formação de profissionais da educação: Visão crítica e perspectiva de mudança. Educação \& Sociedade, vol.20, n.68. Campinas Dec. 1999. https://doi.org/10.1590/S0101-73301999000300013 LOCKE, Edwin A.; LATHAM, Gary P.. A Theory of Goal Setting and Task Perfomance. Englewood Cliffs, N.J.: Prentice Hall, 1990.

LOCKE, Edwin A.. Job satisfaction. In: Gruneberg M.; Wall, T. (Eds.). Social psychology and organizational behavior. New York: John Wiley \& Sons, 1984.

MASLOW, Abraham H.. Motivation and personality. Nova York: Harper \& Row, 1954. MILES, Matthew B.; HUBERMAN, Michael. Qualitative data analyses. London: Sage, 1994.

MATARUCA, Isabel Vasco Mamude. Profissionalidade docente: um olhar sobre a condição de trabalho do formador do Instituto de Formação de Professores de Chongoene. New Trends in Qualitative Research, v.2, p. 297-311, 7 Jul. 2020. https://doi.org/10.3636/ntqr.2.2020.297-311

MOURA, Tania Maria de Melo. Formação de educadores de jovens e adultos: realidade, desafios e perspectivas atuais, Práxis Educacional, Vitória da Conquista, v. 5, n. 7, p. 45-72, jul./dez 2009.

PRETI, Dino (Org.). O discurso oral culto. 2ª . Edição. São Paulo: Humanitas Publicações - FFLCH/USP, 1999.

RAMALHO, Betânia Leite; NUÑEZ, Isauro Beltrán; GAUTHIER, Clermont. Formar o professor, profissionalizar o ensino: perspectivas e desafios. 2. ed. Porto Alegre: Sulina, 2004.

República de Moçambique. Resolução ํo12/2015, de 14 de Abril, Aprova o Programa Quinquenal do Governo - PQG 2015-2019, Boletim da República ำ29, I Série. Maputo: Imprensa Nacional, 2015.

SILVA, Reinaldo O. da. Teorias da administração. São Paulo: Pearson Prentice Hall, 2008.

STAKE, Robert E.. A arte de investigação com estudo de caso. $2^{\underline{a}}$ edição. Lisboa: Fundação Calouste Gulbenkian, 2009.

STIGGINS, Richard J.. Student-involved classroom assessment (5th edition). Columbus, Ohio: Merrill Prentice Hall, 2008.

VROOM, Victor Harold. Work and motivation. Nova York: Wiley, 1964. 